\title{
ATOS DE

ISSN: 1809-0354

\section{VIVÊNCIA DE PRÁTICAS INCLUSIVAS EM SALA DE AULA: POSSIBILIDADES A PARTIR DO DESENHO UNIVERSAL PARA A APRENDIZAGEM}

EXPERIENCE OF INCLUSIVE PRACTICES IN THE CLASSROOM: POSSIBILITIES FROM THE UNIVERSAL DESIGN FOR LEARNING

\section{EXPERIENCIA DE PRÁCTICAS INCLUSIVAS EN EL SALÓN DE CLASES: POSIBILIDADES DEL DISEÑO UNIVERSAL PARA EL APRENDIZAJE}

\author{
SILVA, Gabrielle Lenz da \\ gabelenz@hotmail.com \\ UFPel - Universidade Federal de Pelotas \\ https://orcid.org/0000-0002-5112-966X \\ CAMARGO, Síglia Pimentel Höher \\ sigliahoher@yahoo.com.br \\ UFPel - Universidade Federal de Pelotas \\ https://orcid.org/0000-0001-7058-6519
}

RESUMO: Uma escola inclusiva garante o direito universal à educação, assegurando a matrícula, o acesso e a permanência de todos os alunos na escola comum, atendendo as necessidades individuais de todos os alunos. O Desenho Universal para a Aprendizagem (DUA) surge como uma nova forma de organização escolar, na qual se elabora estratégias de ensino e acessibilidade pensando em todos os alunos, utilizando-se de formas de ensino diferenciadas. Com isso, o presente relato de experiência tem como objetivo apresentar formas práticas de inclusão observadas em um contexto estadunidense, bem como relacioná-las com o debate atual sobre o tema. As vivências demonstraram que a equidade está presente nas atividades propostas, pois são planejadas seguindo os princípios do DUA e com base na importância de conhecer o aluno e pensar nas suas necessidades de aprendizagem.

Palavras-chave: Inclusão Educacional. Prática pedagógica. Estratégias Educacionais. Desenho Universal para a Aprendizagem

ABSTRACT: An inclusive school guarantees the universal right to education, ensuring that all students are able to enroll, access, and remain in a common school that meets the individual needs of all students. Universal Design for Learning (UDL) has emerged as a new form of school organization in which teaching and accessibility strategies are designed with all students in mind using a variety of teaching methods. This experience report aims to present practical forms of inclusion observed in a North American context and relate them to the current debate on the topic. The experiences demonstrated that the proposed activities are equitable since they are planned 


\section{ATOS DE

according to UDL principles, emphasizing the importance of knowing the student and thinking about their learning needs.

Keywords: Educational Inclusion. Pedagogical practice. Educational Strategies. Universal Design for Learning

RESUMEN: Una escuela inclusiva garantiza el derecho universal a la educación, asegurando la matriculación, acceso y permanencia de todos los estudiantes en la escuela común, atendiendo las necesidades individuales de todos los alumnos. El Diseño Universal para el Aprendizaje (DUA) surge como una nueva forma de organización escolar, en la que se diseñan estrategias de enseñanza y accesibilidad para todos los estudiantes, utilizando diferentes métodos de enseñanza. De esta manera, este informe de experiencia tiene como objetivo presentar formas prácticas de inclusión observadas en el contexto estadounidense, y relacionarlas con el debate actual sobre el tema. Las experiencias demostraron que la equidad está presente en las actividades propuestas, ya que se planificaron siguiendo los principios de la DUA, y se basaron en la importancia de conocer al alumno y pensar en sus necesidades de aprendizaje.

Palabras clave: Inclusión Educativa. Práctica pedagógica. Estrategias educativas. Diseño Universal para el Aprendizaje

\section{INTRODUÇÃO}

A palavra inclusão, segundo o dicionário on-line Michaelis, significa "ato ou efeito de incluir(-se); introdução de uma coisa em outra, de um indivíduo em um grupo etc.; inserção". O oposto de incluir é excluir. Então, levando em consideração estes significados e refletindo sobre as ações que eles implicam, inclusão é quando deixamos de excluir algo ou alguém que antes não era considerado do mesmo grupo, era colocado à parte e isolado dos demais. A inclusão defende o direito de todos de participarem, opinarem e pertencerem ao que antes lhes era distante, seja no âmbito social, educacional, trabalhista, etc. (RODRIGUES, 2006). Quando falamos especificamente de inclusão educacional, logo vem à nossa mente a inclusão de alunos com deficiências e/ou transtornos, aqueles que apresentam necessidades educacionais especiais (NEE), ou seja: os alunos público-alvo da educação especial (PAEE). No entanto, há outros grupos que foram e ainda têm sido social, escolar e historicamente marginalizados, a quem a escola também pertence, devendo recebêlos e se adequar a eles. Sendo assim, o que de fato significa tornar uma escola inclusiva? 


\section{ATOS DE \\ PESQUISA \\ EM EDUCAÇÃO}

ISSN: 1809-0354

3

Segundo Redig, Mascaro e Dutra (2017), uma escola inclusiva garante o direito universal à educação, assegurando, assim, a matrícula, o acesso e a permanência de todos os alunos na escola e em salas de aulas comuns. Entretanto, para além do direito de estar na escola, a educação inclusiva diz respeito ao atendimento das necessidades individuais de todos os alunos, pensando em formas de ensinar a todos, levando em consideração seu nível de aprendizagem, questões culturais e sociais, bem como possíveis déficits na aquisição do conteúdo trabalhado. Glat, Pletsch e Fonte (2007) corroboram com Redig, Mascaro e Dutra (2017) quando reafirmam que a inclusão escolar não é somente estar na escola e que esta não pode ser vista somente como uma oportunidade de socialização; promover a inclusão escolar significa pensar e agir na permanência destes alunos na escola, tendo como objetivo principal o sucesso acadêmico. Para Zerbato e Mendes (2018, p. 148, 2018), a inclusão escolar "requer mais que intenções e documentos que garantam o direito à educação para todos; ações práticas capazes de atender as diversas demandas dos alunos (PAEE ou não) são necessárias, além de oferecer-Ihes situações ricas de aprendizagem". A inclusão escolar é um processo infinito, ou seja, é feito diariamente e não tem prazo para terminar; é constante e sempre atenta às possíveis barreiras para o aprendizado, tanto físicas quanto acadêmicas; é justa, pois propicia o acesso, a participação e o progresso de todos os alunos; é universal, pois não é somente para atender alguns alunos, é para todos de acordo com as suas necessidades, principalmente para aqueles em risco de exclusão, que são marginalizados e possivelmente fadados ao insucesso escolar (RODRIGUES, 2006).

Cabe ressaltar ainda que, quando se fala em sucesso acadêmico ou aproveitamento escolar, não há como medir o sucesso ou avanço escolar de alunos "diferentes", levando em consideração "medidas" iguais. Cada aluno tem seu ritmo de desenvolvimento, sua forma de aprender, sua carga cultural e questões sociais que permeiam o seu processo de ensino/aprendizagem. Por isto, é necessário que o aluno seja avaliado de acordo com ele mesmo, medindo seu progresso com base no conhecimento prévio que ele tinha.

Ao reconhecer que os alunos são diferentes entre si, é preciso ter em mente que estes podem apresentar diferentes habilidades que são utilizadas para alcançar o desenvolvimento acadêmico, bem como a necessidade de utilizar diferentes meios 


\section{ATOS DE

e recursos para o sucesso escolar. Há a teoria de que os alunos apresentam estilos de aprendizados diferenciados, como visual, auditivo e cinestésico, em que o indivíduo visual tem mais facilidade de aprender ao fazer anotações do conteúdo trabalhado e também em aulas que apresentam o conteúdo escrito no quadro ou slides; já o auditivo aprende ao ouvir e falar informações em voz alta; finalmente, o cinestésico prefere atividades práticas, que exijam movimento e "mão na massa". É importante ressaltar que também pode haver a combinação entre estes estilos (SCHMITT; DOMINGUES, 2016). Existe também a Teoria das Inteligências Múltiplas (GARDNER, 1995), que apresenta sete diferentes tipos de inteligências (espacial, musical, lógicomatemática, interpessoal, corporal-cinestésica, linguística e intrapessoal), que podem ser apresentadas pelos indivíduos para solucionar problemas (BESSA, 2008). Embora o indivíduo tenha uma inteligência, segundo Gardner (1995), que se sobressai às outras, este também apresenta as outras em níveis mais baixos ou menos estimulados. O fato é que alunos necessitam de suportes, recursos e formas diferentes de ensino. No entanto, dependendo do nível de aprendizagem do aluno, bem como de suas características, habilidades e dificuldades, será necessário apresentar estratégias, materiais e suportes diferenciados de acordo com suas necessidades, para que ele alcance o sucesso acadêmico. É preciso dar o necessário para que o aluno progrida, o que para uns pode ser pouco suporte e para outros muito, ou seja, os estudantes também necessitam de suportes diferenciados durante as aulas para que tenham progresso no aprendizado. Segundo o Center for Applied Special Technology (CAST) (2011, p.5) "os alunos diferem no modo como percebem e compreendem a informação que lhes é apresentada". Devido a isto, o conceito de inclusão escolar está intimamente relacionado com o conceito de equidade no ensino. Segundo Tenório, Ferraz e Pinto (2015, p. 8), a equidade na educação

implica em reconhecer que nem todos aprendem ou devem ser ensinados da mesma forma igualitária, pois um processo educacional que busca a equidade pressupõe o reconhecimento e o respeito às diferenças e é capaz de fazer com que todos os alunos desenvolvam as competências e habilidades esperadas para o nível de estudo, levando em consideração as diferenças pessoais, socioeconômicas e culturais do aluno. Assim, se faz necessário que a escola não seja indiferente com as diferenças e trate de forma diferente a partir de suas necessidade e subjetividades os desiguais, pois se todos são tratados igualmente, a desigualdade permanece. 


\section{ATOS DE

Frente aos conceitos de inclusão escolar e equidade no ensino, o Desenho Universal para a Aprendizagem (DUA) - Universal Design for Learning (UDL) - surge nos Estados Unidos, em 1999, através do CAST e apoiado pelo Departamento de Educação dos Estados Unidos, como uma nova forma de organização escolar. No DUA, elaboram-se estratégias de ensino e acessibilidade pensando em todos os alunos para que aprendam juntos, porém utilizando formas diferenciadas (ZERBATO; MENDES, 2018). Em uma aula planejada levando em consideração os conceitos do DUA, o mesmo conteúdo é apresentado de diversas maneiras a todos os alunos, pensando em possibilidades de um ensino que englobe todas as formas de aprender, bem como elimine quaisquer barreiras à aprendizagem. O DUA se preocupa em aplicar uma prática pedagógica que identifica modelos auxiliares para uma plena inclusão escolar, garantindo a participação e o sucesso acadêmico de todos os alunos juntos, utilizando-se de poucas individualizações no ensino e fazendo com que de fato a educação seja inclusiva (NUNES; MADUREIRA, 2015). O CAST (2011, p. 4) enfatiza que:

Em ambientes de aprendizagem, como escolas e universidades, a variabilidade individual é a norma, não a exceção. Quando os currículos são projetados para atender às necessidades de uma "média" imaginária, eles não abordam a variabilidade da realidade do aluno. Eles falham em proporcionar a todos os indivíduos oportunidades justas e iguais de aprender, excluindo os alunos com diferentes habilidades, antecedentes e motivações que não atendem aos critérios ilusórios de "média". (Tradução nossa $\left.{ }^{1}\right)$.

O planejamento, elaborado levando em consideração as características do DUA, deve ser orientado por três princípios norteadores (CAST, 2011):

I. Proporcionar Múltiplos Modos de Apresentação: este princípio diz respeito ao "o que" da aprendizagem, ou seja, a forma como os conteúdos são apresentados e trabalhados, utilizando-se de variadas formas de apresentação. Pode ser dividido nas seguintes três subcategorias: proporcionar opções para a percepção; oferecer opções

\footnotetext{
${ }^{1}$ In learning environments, such as schools and universities, individual variability is the norm, not the exception. When curricula are designed to meet the needs of an imaginary "average", they do not address the reality learner variability. They fail to provide all individuals with fair and equal opportunities to learn by excluding learners with different abilities, backgrounds, and motivations who do not meet the illusive criteria for "average".
} 


\section{ATOS DE \\ PESQUISA \\ EM EDUCAÇÃO}

ISSN: 1809-0354

para o uso da linguagem, expressões matemáticas e símbolos; e oferecer opções para a compreensão.

II. Proporcionar Múltiplos Modos de Ação e Expressão: neste princípio, discute-se o "como" da aprendizagem, ou seja, a respeito das diversas formas que o aluno se relaciona com o que está aprendendo, bem como expressa seu conhecimento. Este é dividido em três subcategorias: proporcionar opções para a atividade física; oferecer opções para a expressão e comunicação; e oferecer opções para as funções executivas.

III. Proporcionar Múltiplos Modos de Engajamento: refere-se ao "porquê" da aprendizagem e está intimamente ligado aos aspectos emocionais e motivacionais presentes no processo de ensino/aprendizado. Este princípio também possui três subcategorias: proporcionar opções para incentivar o interesse; oferecer opções para o suporte ao esforço e à persistência; e oferecer opções para a autorregulação.

O processo de inclusão escolar não é somente responsabilidade do professor, mas também de toda a comunidade escolar. Ou seja, toda a escola precisa se reestruturar para acolher todos os alunos com suas histórias e vivências, capacidades e dificuldades, para que assim todos desenvolvam seu potencial máximo. A questão principal da inclusão escolar se refere à identificação de "metodologias de ensino facilitadoras da participação e da aprendizagem de todos, o que significa a transição do paradigma centrado no aluno para o paradigma centrado na escola" (LOPÉZ, p. 181, 2012).

Buscando ampliar a discussão a respeito da inclusão escolar, bem como sobre equidade no ensino a partir do DUA, o presente relato de experiência tem como objetivo apresentar formas práticas de inclusão observadas em um contexto estadunidense, bem como relacioná-las ao debate atual sobre o tema.

\section{MÉTODO E DESENVOLVIMENTO}

O relato de experiência apresenta-se como um texto descritivo, no qual uma experiência vivida é relatada de acordo com o que foi observado. Ao dialogar com o 


\section{ATOS DE \\ PESQUISA \\ EM EDUCAÇÃO}

ISSN: 1809-0354

7

referencial teórico, que reafirma, argumenta e/ou discute o que foi vivenciado, o relato de experiência se torna de grande importância para a área de atuação abordada. Além das experiências vividas durante as observações e vivências, este tipo de relato apresenta as motivações do observador, bem como o seu olhar crítico sobre a prática. Segundo Daltro e Faria $(2019$, p. 235), o relato de experiência "configura-se como narrativa que, simultaneamente, circunscreve experiência, lugar de fala e seu tempo histórico, tudo isso articulado a um robusto arcabouço teórico, legitimador da experiência enquanto fenômeno científico".

A experiência foi realizada em uma escola regular na cidade de Bethune, estado do Colorado, Estados Unidos, durante janeiro de 2020. A escola faz parte de uma comunidade pequena e também recebe estudantes de pequenos municípios da região. Nas cidades ao redor, também há diversas famílias de origem mexicana, muitas das quais ainda não dominam o idioma inglês. Na escola há turmas desde a pré-escola até o último ano do ensino médio. A turma na qual foi feita a observação é multisseriada, com alunos dos $1^{\circ}$ e $2^{\circ}$ anos do ensino fundamental. Havia 13 alunos na turma, sendo seis do $1^{\circ}$ ano e sete do $2^{\circ}$ ano do ensino fundamental, dos quais dois eram de origem mexicana e estavam aprendendo o inglês, um era autista e os demais estavam em níveis diferentes e tinham suas formas diferenciadas de aprender. A professora participante é formada em Elementary Education, ou seja, é habilitada para trabalhar com os anos iniciais do ensino fundamental e é Mestre em Education of students with diversities, o que corresponde à habilitação para trabalhar com estudantes que aprendem o inglês como a segunda língua. Ela leciona há 35 anos. Os dados foram coletados através de observações realizadas diariamente, durante uma semana, no período de oito horas de aula, além de entrevistas informais com a professora da turma.

\section{PRÁTICAS INCLUSIVAS EM SALA DE AULA}

Nos Estados Unidos, país em que foram feitas as observações, a inclusão escolar é debatida e estruturada desde 1980, período no qual foram feitas diversas mudanças pedagógicas e financeiras que viriam a resultar em um olhar mais atento à educação e ao ensino de todos os alunos, considerando suas particularidades (U.S., 


\section{ATOS DE \\ PESQUISA \\ EM EDUCAÇÃO}

ISSN: 1809-0354

8

1975). A palavra e o conceito de inclusão começaram a ser utilizados nas escolas, as quais passaram a ter uma maior aceitação das diferenças individuais e a criar estratégias que fossem ao encontro das necessidades de todos os estudantes, a partir de discussões e documentos como o Regular Education Initiative, proposto por Madeleine Will em 1986, e o Full Inclusion (MENDES, 2006). Outras leis também foram implementadas naquele país, almejando uma melhor participação, aproveitamento e sucesso acadêmico de todos os alunos, garantindo assim um acesso equitativo ao processo de ensino e aprendizagem, como No Child Left Behind (U.S., 2001) e Every Student Succeeds Act (U.S., 2015).

Ao adentrar em uma sala de aula com um contexto diferente do que está acostumada, o olhar da pesquisadora estava direcionado às práticas inclusivas e seus desdobramentos. Em um primeiro momento o olhar percorreu toda a sala e a pesquisadora viu a diferença entre as salas que já vivenciou e aquela que trazia algo novo. Era uma sala cheia de recursos pedagógicos, livros infantis e pistas visuais em todas as paredes. Via-se explicações sobre adição e subtração, sobre unidade, dezena e centena, sobre agrupamento e pareamento. No quadro branco tinha o alfabeto e embaixo de cada letra haviam palavras escritas pelas crianças para consultas futuras durante as atividades de escrita de textos. Os recursos ficavam à disposição das crianças, as quais os usavam com autonomia e organização. Era uma sala de aula colorida, parecia bagunçada em um primeiro momento, mas depois viase que tudo estava perfeitamente em seu lugar.

Como o foco principal da observação eram as práticas inclusivas utilizadas, após a ambientação com aquela sala de aula diferente, a pesquisadora indagou à professora a respeito do planejamento para os alunos, visto que haviam estudantes com deficiência, de outras culturas e com níveis diferentes de aprendizagem. A professora relatou que, para o aluno com Transtorno do Espectro do Autismo havia o Planejamento Educacional Individualizado (PEI). O PEI é uma ferramenta que contribui para a escolarização de alunos com NEE. Ele é elaborado pelo professor titular, professor do AEE (ou educador especial, como no caso dos Estados Unidos), família do aluno e demais profissionais que o atendem. Para a elaboração do PEI deve-se considerar o que o aluno já sabe, bem como suas habilidades consolidadas e o que ainda está em desenvolvimento, sua idade cronológica, a série em que está, 


\section{ATOS DE \\ PESQUISA \\ EM EDUCAÇÃO}

ISSN: 1809-0354

9

os conteúdos da série e, a partir disto, avaliar e formular objetivos específicos para aquele aluno (GLAT; VIANNA; REDIG, 2012). Segundo a professora da turma, os objetivos, metodologias e estratégias presentes no PEI guiam o planejamento que ela faz para toda a turma, pois considera que muitas destas estratégias e recursos podem contribuir para a aprendizagem de todos.

Pensando na aprendizagem como um fruto de interações sociais com os pares, observou-se que a sala de aula é quase sempre organizada em grupos de três ou quatro alunos. Nestes grupos, a professora relatou sempre colocar alunos em níveis diferentes de aprendizagem, até mesmo alunos do $1^{\circ}$ e $2^{\circ}$ anos juntos. Ela relatou que esta troca entre os colegas é muito importante, pois uns aprendem com os outros, até mesmo aqueles que estão em um maior nível que os demais. A fala da professora evidencia as propostas de mediação da aprendizagem enfatizadas por Vygotsky (1984), em que o desenvolvimento cognitivo se produz através de um contexto rico em interações sociais. O autor também reforça que é através dessa troca com os pares mais competentes que os alunos estarão aptos a executar tarefas e decisões de forma independente mais tarde, pois é através da solução de problemas em grupos que as crianças vão aprendendo a ponderar as diversas situações e assim optar pela melhor solução. Nos momentos em que as crianças trabalhavam individualmente, a professora estava a todo momento interagindo com elas, indagando sobre a atividade e respondendo às perguntas. Esta dinâmica de trabalhar em grupos e individualmente vai ao encontro do $3^{\circ}$ princípio do DUA - Fornecer Múltiplos Meios de Engajamento pois, considerando que cada aluno tem sua forma de se engajar na atividade e assim de acessar o conteúdo, as aulas são pensadas para promover a colaboração e ao mesmo tempo a individualidade e autonomia, trazendo, assim, incentivos ao interesse, ao esforço e à persistência (CAST, 2011).

Outro ponto importante a ser destacado na divisão da sala em grupos é que, em certos momentos, os grupos são utilizados para trabalhar o mesmo conteúdo, porém de maneiras diversas. Enquanto um grupo utiliza o tablet (recurso disponível para os alunos desta escola) para realizar tarefas em forma de jogos (que são previamente selecionados pela professora e possuem níveis de dificuldades diferentes), outro realiza uma atividade em uma folha impressa (durante a atividade eles podem utilizar os recursos disponíveis na sala), um grupo pode escolher uma 


\section{ATOS DE

atividade livre (este momento seria de descanso para os alunos, enquanto os outros grupos trabalham) e, por fim, um outro grupo trabalha com o auxílio da professora. Cada grupo fica um determinado tempo em cada "estação de aprendizagem". A professora relatou que este momento é muito importante para ela ter uma atenção mais focada em cada um dos alunos, pois como atende somente três ou quatro estudantes por vez, ela consegue observar mais atentamente as suas necessidades individuais e assim planejar diferentes formas de ensiná-los. Segundo os preceitos do DUA, a avaliação das aprendizagens dos alunos deve ser sistemática, contínua e flexível para, além de reconhecer os conceitos e conteúdos já assimilados pelos estudantes, também "recolher informação que ajude os docentes a ajustarem o seu ensino e a maximizarem a aprendizagem" (HICHCOCK et al., 2002, p. 13).

Esta ação de ensinar um conteúdo de diferentes formas e também de estar atenta às necessidades de cada aluno para assim planejar uma aula que atenda a todos está intimamente ligada ao 1 Princípio do DUA - Fornecer Múltiplos Modos de Apresentação -, que instrui a respeito de diversas formas de apresentar o conteúdo, estimulando a percepção e a compreensão do que está sendo trabalhado (CAST, 2011). Assim, o DUA consiste em uma forma diferenciada de elaborar a prática educacional,

com a flexibilização da maneira como a informação é apresentada, na maneira como os estudantes respondem ou expressam conhecimentos e habilidades e como os discentes estão engajados. Com isso, chega-se a uma diminuição das barreiras no ensino, propiciando acomodações condignas, o apoio aos desafios e, por fim, mantendo as expectativas de grandes realizações para todos os estudantes [...] Uma elaboração de condições de aprendizagens flexíveis, de simples utilização e cativantes para todos os estudantes, tornando o currículo mais acessível para os estudantes com incapacidades e, ao mesmo tempo, criando possibilidades de aprendizagem a todos (RICARDO; SAÇO; FERREIRA, 2017, p.1529).

Ainda trabalhando com conceitos do DUA, a pesquisadora observou que, durante as aulas, as crianças não copiam a matéria do quadro. Ao ser questionada a respeito disto, a professora respondeu que não passa atividades no quadro devido ao fato de ter alunos não só de séries diferentes, mas também em níveis de aprendizagem distintos. Ela acredita que copiar não traz benefícios para a aprendizagem, pois, se o fizessem, os estudantes perderiam o tempo de executar uma tarefa, gastando-o apenas em copiar. Por já ter trabalhado muito com a divisão de 


\section{ATOS DE \\ PESQUISA \\ EM EDUCAÇÃO}

ISSN: 1809-0354

11

grupos citada anteriormente, ela diz que assim já consegue ter uma noção de como a criança está se relacionando com os conteúdos trabalhados, não precisando corrigir as tarefas no caderno. Foi observada somente uma atividade de cópia durante o período observado: após uma atividade de leitura de um livro literário e confecção coletiva de um cartaz que continha as cenas, personagens, questão e moral da história, os alunos receberam uma folha na qual tinham que copiar o que haviam preenchido no cartaz para levarem para casa e recontarem a história para as famílias.

As atividades de leitura são realizadas diariamente, tanto de forma coletiva, quanto individualmente. Na leitura coletiva, todos os alunos e a professora sentam-se em um tapete em frente a um cartaz. A professora primeiramente mostra a capa do livro e todos leem juntos o título da obra. Após este primeiro contato, os alunos são estimulados a pensar a respeito da história, em como seriam os personagens, como a história se desenrolaria, qual seria o seu final, etc. Todas as inferências feitas pelos estudantes são escritas no cartaz para posterior comparação. A professora lê a história de forma lúdica e prazerosa e, ao final, alunos e professora comparam a história com as suposições feitas anteriormente.

$\mathrm{Na}$ leitura individual, os alunos podem escolher na estante da sala de aula os livros que quiserem, desde que estejam de acordo com o seu nível de leitura (falaremos sobre isto mais adiante). Para aqueles alunos que a professora reconhece um atraso em relação aos colegas, é solicitado o acompanhamento de um "tutor" mais experiente. Este tutor geralmente é um aluno do ensino médio liberado alguns minutos antes de sua aula para acompanhar a leitura dos alunos mais novos. Além de acompanhar a leitura e estimular os alunos a lerem mais fluentemente, os "tutores" devem relatar para a professora como foi a leitura do aluno que estavam acompanhando.

Segundo Gomes e Boruchovich (2019), há estratégias que podem ser utilizadas em sala de aula para motivar os alunos à leitura e também para melhorar sua fluência. As estratégias utilizadas pela professora e citadas anteriormente são baseadas na autorregulação da aprendizagem de leitura (LOPES, 1997; BORUCHOVITCH, 1999). Gomes e Boruchovich (2019) relatam que é extremamente importante ensinar aos alunos estratégias cognitivas e metacognitivas para a leitura e que o professor tem o dever de trabalhá-las com seus alunos. Estes autores também 


\section{ATOS DE \\ PESQUISA \\ EM EDUCAÇÃO}

ISSN: 1809-0354

frisam a importância de se trabalhar com a leitura de diversas formas e meios, assim como de utilizar livros que estejam de acordo com o nível de leitura da criança: se o livro for muito difícil de ler, o estudante se desmotivará. Novamente vemos a importância de conhecer o aluno e ter a ciência de que fase este se encontra com o intuito de, além de promover o seu progresso, manter a sua motivação em aprender.

Após trabalhar com a leitura de livros, tanto coletiva quanto individualmente, a professora passa a tarefa de escrita de textos para os alunos. No entanto, ao invés de sentarem-se em suas mesas e escreverem um texto, eles vão até o armário e pegam sua pasta de escrita. Nesta pasta existem várias estratégias de autorregulação da escrita para guiar os estudantes nesta tarefa. Eles têm acesso a dicas de escrita como: iniciar a frase com letra maiúscula, colocar espaço entre as palavras, usar pontuação ao final da frase e utilizar-se dos sons das letras caso não saibam escrever uma determinada palavra.

Eles também possuem seus próprios "dicionários de escrita", o qual eles completam com novas palavras, as que não sabiam escrever anteriormente. Ao adicionar uma palavra nova no seu dicionário, eles também a adicionam no quadro branco, embaixo da letra inicial correspondente, para que todos os colegas tenham conhecimento desta.

No momento em que iniciam a história, recebem uma folha para ser usada como rascunho da escrita, na qual eles escrevem os nomes dos personagens, as cenas em que a história se desenrolaria e o seu final. Após escreverem o rascunho, eles desenham o que escreveram e só depois desenvolvem sua escrita final. Este processo de escrita não se dá em um único dia e é estimulado diariamente. Ao final da semana, eles terminam a escrita do texto e o guardam em sua pasta de escrita, na parte dos textos terminados. Essas estratégias utilizadas pela professora também são citadas por Gomes e Boruchovitch (2019) como eficazes para a autorregulação da escrita, pois fazem com que os alunos reflitam sobre o que irão escrever antes de realmente fazê-lo, infiram sobre o que irá acontecer na história e mudem ou acrescentem algo, se necessário.

A professora avalia a escrita dos alunos de acordo com as escritas anteriores, o que vai ao encontro dos conceitos do DUA, visto que cada estudante será avaliado de acordo com seu próprio progresso e da forma como ele melhor se encaixa em seu 


\section{ATOS DE \\ PESQUISA \\ EM EDUCAÇÃO}

ISSN: 1809-0354

13

próprio perfil (PRAIS; ROSA, 2016). Neste contexto, a avaliação da escrita parte do que o aluno produziu anteriormente e verifica, assim, o quanto sua escrita melhorou. Assim, a professora também tem consciência de quem precisa de mais apoio na hora da escrita e pode pensar em novas estratégias para otimizar a aprendizagem de todos, inclusive do seu aluno com deficiência.

Trabalhar com a autorregulação, tanto voltada para as estratégias de aprendizagem citadas anteriormente, quanto de motivação e regulação da emoção são diretrizes presentes no $3^{\circ}$ princípio do DUA - Proporcionar Múltiplos Modos de Engajamento. É necessário pensar em formas de planejar uma aula que dê conta de oferecer opções para a autorregulação, seja promovendo antecipações que aumentem a motivação (o que foi apresentado nas vivências das atividades de leitura e escrita), estimulando a capacidade de superar dificuldades (tanto em grupos, quanto individualmente) e possibilitando a autoavaliação e reflexão (CAST, 2011).

Durante o período de observação, a pesquisadora pôde acompanhar o momento em que os alunos estavam fazendo o teste de leitura. $O$ teste foi feito fora da sala de aula, a fim de minimizar as distrações durante a leitura. A forma como o teste foi aplicado era individualizada: havia uma caixa com livros classificados de A a $Z$, com cada letra representando um grau de dificuldade diferente. Cada letra continha dois livros, dos quais os alunos podiam escolher um. Juntamente com os livros vinha a sua transcrição em uma ficha, com uma classificação do lado.

O aluno iniciava a leitura em voz alta e a professora a acompanhava na ficha, fazendo as marcações quando havia erros. Os erros eram classificados em: significado - quando o aluno errava a leitura da palavra, mas falava outra que era escrita de forma parecida e com o mesmo significado; erro de sintaxe; e erro visual no qual o aluno falava outra palavra similar sem ter relação com o significado da palavra original. Em certo momento do livro, o aluno passava a lê-lo mentalmente. Após terminar, a professora indagava sobre como o livro terminou, avaliando, assim, a capacidade de compreensão e interpretação.

O tempo de leitura também foi cronometrado para avaliar a fluência. Novamente, cada aluno era avaliado de acordo com ele mesmo, analisando e comparando seus níveis de leitura anterior e atual, além de seus erros e fluência. $O$ 2o Princípio do DUA - Proporcionar Múltiplos Modos de Ação e Expressão - apresenta 


\section{ATOS DE \\ PESQUISA \\ EM EDUCAÇÃO}

ISSN: 1809-0354

alguns objetivos que um planejamento deve seguir para que se consiga abarcar todos os alunos; dentre eles, está "Orientar o Estabelecimento de Metas Adequadas" (CAST, 2011). Na avaliação da leitura apresentada anteriormente, pôde-se verificar claramente que a meta para cada aluno foi estabelecida de forma genuína, visto que cada tinha uma meta individual, a qual foi estabelecida de acordo com seu avanço anterior.

A pesquisadora notou que a professora da sala de aula avaliada não utiliza as mesmas formas de ensinar para todos os seus estudantes. Além disso, ela não compara os alunos entre si e não aplica um mesmo teste para todos. Ela compreende que eles são estudantes diferentes, com desenvolvimentos diferentes, ritmos diferentes, vindos de contextos diferentes e com interesses diferentes. É notável a importância de se diferenciar o acesso ao currículo, ou seja, elaborar diferentes formas de ensinar e empregar diferentes recursos, materiais e técnicas para favorecer todos os alunos e garantir o seu sucesso acadêmico. O processo de ensinar por parte do professor não deve esperar que todos aprendam tudo, mas entender que cada um apresenta e responde de forma diferenciada aos processos de ensino/aprendizagem (PLETSCH; SOUZA; ORLEANS, 2017).

Esses relatos demonstram o quanto o conceito e a aplicabilidade do DUA pode ser um avanço na inclusão de todos os alunos e em seu processo de aprendizagem, pois permite que todos acessem o currículo geral ao mesmo tempo em que personaliza as formas de ensinar; ou seja, respeita os estilos, tempos e habilidades dos alunos ao utilizar formas diferenciadas de ensinar. Demonstram, também, o quanto estratégias de autorregulação da aprendizagem são eficazes para que todos os alunos, com suas peculiaridades e individualidades, desenvolvam-se em atividades de leitura e escrita.

\section{CONCLUSÃO}

Embora as observações do presente relato de experiência tenham ocorrido em um outro país, com cultura e situação econômica diferentes das nossas, em nenhum momento o objetivo deste relato é comparar práticas realizadas nos Estados Unidos com as realizadas no Brasil e classificá-las como melhores ou superiores. Sabemos 


\section{ATOS DE \\ PESQUISA \\ EM EDUCAÇÃO}

ISSN: 1809-0354

das condições culturais, sociais e econômicas que se impõem ao trabalho do docente brasileiro, que possui e cria suas ferramentas de trabalho de forma igualmente produtiva. Mediante as dificuldades e os desafios dos professores em incluir seus alunos com deficiência, os quais têm sido amplamente relatados pela literatura brasileira (e.g., ANJOS; ANDRADE; PEREIRA, 2009; SILVEIRA; ENUMO; ROSA, 2012), o intuito deste relato de experiência é mostrar diferentes possibilidades e formas simples de incluir todos os alunos nas aulas e de ter um olhar atento às suas individualidades, para que, assim, possa-se pensar em formas de todos acessarem um mesmo currículo de maneiras distintas.

As atividades relatadas se encaixam nos conceitos do DUA (NUNES; MADUREIRA, 2015), pois apresentam o conteúdo de diferentes formas, permitem que o aluno expresse seu entendimento e compreensão do que foi trabalhado de diferentes maneiras, demonstram que a professora planejou as atividades de maneira que promovesse $o$ interesse e engajamento dos alunos e também respeitam as suas particularidades, não exigindo algo distante da realidade apresentada pelo aluno naquele momento. Estas vivências também demonstram o quanto a equidade está presente em todas as atividades propostas, visto que cada estudante recebe aquilo que necessita para progredir, independente do que os outros colegas estejam recebendo. Percebeu-se ainda, durante as observações, que não há a necessidade de grandes esforços para incluir todos os alunos nas atividades de sala de aula. $O$ principal e o que guiará todo o planejamento é algo simples: conhecer o aluno e pensar nas suas necessidades particulares de aprendizagem.

\section{GABRIELLE LENZ DA SILVA}

Pedagoga e Mestre em Educação pela Universidade Federal de Pelotas - UFPel. Doutoranda em Psicologia na Universidade Federal do Rio Grande do Sul - UFRGS.

\section{SÍGLIA PIMENTEL HÖHER CAMARGO}

Psicóloga pela Universidade Federal de Santa Maria - UFSM. Mestre em Psicologia pela Universidade Federal do Rio Grande do Sul - UFRGS. Doutora em Psicologia Educacional pela Texas A\&M University. Professora adjunta da Faculdade de Educação e programa de pós-graduação em Educação da Universidade Federal de Pelotas - UFPel.

\section{REFERÊNCIAS}




\section{ATOS DE \\ PESQUISA \\ EM EDUCAÇÃO}

ISSN: 1809-0354

ANJOS, H.P.; ANDRADE, E.P.; PEREIRA, M.R. A inclusão escolar do ponto de vista dos professores: o processo de constituição de um discurso. Revista Brasileira de Educação Especial, Marília, v. 4, n. 40, p. 116-129, 2009.

Disponível em: https://www.scielo.br/pdf/rbedu/v14n40/v14n40a10.pdf Acesso em: 07 mai. 2020

BESSA, V. H. Teorias da Aprendizagem. Curitiba, IESDE Brasil S.A., 2008.

BORUCHOVITCH, E. Estratégias de aprendizagem e desempenho escolar: considerações para a prática educacional. Psicologia: Reflexão e Crítica, 12. P 361 376, 1999.

CAST. Center for Applied Special Technology. Universal Design for learning guidelines version 2.0. Wakefield, MA: 2011.

DALTRO, M. R.; FARIA, A. A. Relato de experiência: Uma narrativa científica na pós-modernidade. Estud. pesqui. psicol., Rio de Janeiro, v. 19, n. 1, p. 223-237, 2019. Disponível em:

https://www.e-publicacoes.uerj.br/index.php/revispsi/article/view/43015

Acesso em: 19 dez. 2020

GARDNER, H. Inteligências Múltiplas: a teoria na prática. Trad. Maria Adriana Veríssimo Veronese. Porto Alegre: Artes Médicas, 1995.

GLAT, R.; PLETSCH. M. D.; FONTES, R. de S. Educação inclusiva \& Educação Especial: propostas que se complementam no contexto da escola aberta à diversidade. Revista Educação, v. 32, n. 2, p. 343-355, UFSM, 2007. Disponível em: https://periodicos.ufsm.br/reveducacao/article/view/678 Acesso em: 10 de abril 2020

GLAT, R.; VIANNA, M. M.; REDIG, A. G. Plano Educacional Individualizado: uma estratégia a ser construída no processo de formação docente. Ciências Humanas e Sociais em Revista, p. 79-100, v. 34, n. 12. 2012. Disponível em:

http://www.eduinclusivapesq-

uerj.pro.br/images/pdf/GLAT_VIANNA_REDIG_Artigosemperiodicos_2012.pdf Acesso em: 10 mar. 2020

GOMES, M.A.M.; BORUCHOVITCH, E. Aprendizagem autorregulada: Como promovê-la no contexto educativo? Editora Vozes, 2019.

HITCHCOCK, C., MEYER, A., ROSE, D., \& JACKSON, R. Providing new access to the general curriculum. Universal Design for Learning. Teaching Exceptional Children, 35(2), 8-17, 2002. Disponível em: https://pdfs.semanticscholar.org/5743/742b4d8d578ad651c8ea77fddeaee79705ba.p df Acesso em: 11 fev. 2020.

LOPES, M.C.C. O uso de estratégias cognitivas e metacognitivas no ensino/aprendizagem da leitura no 10 Grau: uma proposta de intervenção. (1997). 


\section{ATOS DE \\ PESQUISA \\ EM EDUCAÇÃO}

ISSN: 1809-0354

17

Dissertação de mestrado, Instituto de Estudos da Linguagem, Universidade Estadual de Campinas. Campinas, SP-

LOPÉZ, J. L. Facilitadores de la inclusión. Revista Educación Inclusiva, 5(1), 175187, 2012. Disponível em:

https://revistaeducacioninclusiva.es/index.php/REl/article/view/229/223 Acesso em: 14 mai. 2020.

MENDES, E. G. A radicalização do debate sobre inclusão escolar no Brasil. Revista Brasileira de Educação, v. 11, n. 33, p. 387 - 405, set./dez. 2006. Disponível em:https://www.scielo.br/scielo.php?pid=S1413-

24782006000300002\&script=sci_abstract\&tIng=pt Acesso em: 03 mar. 2020.

NUNES, C., MADUREIRA, I. Desenho Universal para a Aprendizagem: Construindo práticas pedagógicas inclusivas. Da Investigação às Práticas, 5(2), 126 - 143, 2015. Disponível em: https://repositorio.ipl.pt/handle/10400.21/5211 Acesso em: 25 mar. 2020.

PLETSCH, M. D; SOUZA, F. F; ORLEANS, L. F. A diferenciação curricular e o desenho universal na aprendizagem como princípios para a inclusão escolar. Revista educação e cultura contemporânea, vol. 14, no 35, 2017. Disponível em: http://periodicos.estacio.br/index.php/reeduc/article/viewArticle/3114 Acesso em: 16 mar. 2020.

PRAIS, J. L. S.; ROSA, V. F. Princípios do desenho universal para a aprendizagem: planejamento de atividades pedagógicas para inclusão. Revista do Centro de Educação, Letras e Saúde da UNIOESTE - Campus Foz do Iguaçú, v. 18, ํo 2, 2016. Disponível em:

http://e-revista.unioeste.br/index.php/ideacao/article/view/14005 Acesso em: 04 abr. 2020.

REDIG, A. G.; MASCARO, C. A. A. C.; DUTRA, F. B. S. A formação continuada do professor para a inclusão e o plano educacional individualizado: uma estratégia formativa? Revista Diálogos e Perspectivas em Educação Especial, v.4, n. 1, p. 3344, 2017 - Edição Especial. Disponível em:

http://www2.marilia.unesp.br/revistas/index.php/dialogoseperspectivas/article/view/73 28 Acesso em: 12 fev. 2020.

RICARDO, D. C.; SAÇO, L. F.; FERREIRA, E. L. O desenho universal na educação: novos olhares diante da inclusão do ser deficiente. RIAEE - Revista Ibero-

Americana de Estudos em Educação, v. 12, n. esp. 2, p. 1524-1538, ago./2017. Disponível em:

https://periodicos.fclar.unesp.br/iberoamericana/article/view/10083 Acesso em: 29 mar. 2020.

RODRIGUES, D. Dez ideias (mal) feitas sobre a educação inclusiva. in: (2006) David Rodrigues (org.). Inclusão e Educação: doze olhares sobre a Educação Inclusiva, São Paulo. Summus Editorial, 2006. 


\section{ATOS DE \\ PESQUISA \\ EM EDUCAÇÃO}

ISSN: 1809-0354

SCHMITT, C.S.; DOMINGUES, M.J.C.S. Estilos de aprendizagem: um estudo comparativo. Avaliação, Campinas; Sorocaba, SP, v. 21, n. 2, p. 361-385, jul. 2016. Disponível em: https://www.scielo.br/pdf/aval/v21n2/1982-5765-aval-21-02-00361.pdf Acesso em: 01 abr. 2020

SILVEIRA, K. A.; ENUMO, S. R. F.; ROSA, E. M. Concepções de professores sobre inclusão escolar e interações em ambiente inclusivo: uma revisão da literatura. Rev. bras. educ. espec., Marília, v. 18, n. 4, p. 695-708, Dec. 2012. Disponível em: http://www.scielo.br/scielo.php?script=sci_arttext\&pid=S141365382012000400011\&lng=en\&nrm=iso Acesso em: 18 abr. 2020.

TENÓRIO, R. M.; FERRAZ, M. C. G.; PINTO, J. C. A. Eficácia e equidade: indicadores de qualidade da educação básica no Brasil. Projeto Equidade no Ensino Superior. Faculdade de Educação - FACED, 2015. Disponível em: http://www.equidade.faced.ufba.br/sites/equidade.oe.faced.ufba.br/files/eficacia_e_e quidade_-_indicadores_da_educacao_basica_no_brasil.pdf Acesso em: $16 \mathrm{fev}$. 2020.

U.S. Department of Education. Public Law (PL) 94-142. Education for All Handicapped Children Act. 1975.

U.S. Department of Education. No Child Left Behind Act of 2001, 20 U.S.C. $\S 6319$. U.S. 2001. Disponível em: https://www2.ed.gov/nclb/overview/intro/execsumm.pdf Acesso em: 12 jan. 2020.

U.S. Department of Education. Public Law 114-95. Every Student Succeeds Act, 2015. Disponível em: https://www.ed.gov/esea Acesso em: 12 jan. 2020.

VYGOTSKI, L.S. A Formação social da mente. São Paulo: Martins Fontes; 1984.

ZERBATO, A. P; MENDES, E. G. Desenho universal para a aprendizagem como estratégia de inclusão escolar. Educação Unisinos, 22(2):147-155, abril-junho 2018. Disponível em:

http://revistas.unisinos.br/index.php/educacao/article/view/edu.2018.222.04 Acesso em: 17 mar. 2020.

Recebido em: 01/06/2020.

Aprovado em: 11/02/2021. 